\title{
CLINICAL PROFILE OF PATIENTS WITH CHIKUNGUNYA FEVER
}

\author{
Lydia Solomon ${ }^{1}$, Nitin Kumar2, Navjot Singh ${ }^{3}$ \\ 1Assistant Professor, Department of Medicine, Christian Medical College and Hospital, Ludhiana, Punjab, India. \\ ${ }^{2}$ Assistant Professor, Department of Medicine, Christian Medical College and Hospital, Ludhiana, Punjab, India. \\ 3Professor, Department of Medicine, Christian Medical College and Hospital, Ludhiana, Punjab, India.
}

\section{ABSTRACT}

\section{BACKGROUND}

Chikungunya Fever, though known to be a self-limiting disease, causes severe disabling joint involvement, which in turn lays a significant burden on the health care system. Although mortality related to this illness is low, there is significant interference with the ability of a patient to perform routine daily activities due to polyarthritis. The objective of our study is thus to analyse the clinical profile of patients with Chikungunya fever.

\section{METHODS}

OPD and IPD patients with symptoms of fever and joint pains who presented to a tertiary care center in Ludhiana, Punjab were included in the study. They were tested for Chikungunya (CHIKV IgM antibody) and those who were positive (confirmed cases) were in turn recruited to the study. Their clinical profiles, laboratory features, complications and outcomes were studied.

\section{RESULTS}

A total of 88 patients formed our study group, all of whom tested positive for CHIKV IgM antibody. Male:Female ratio was 1:1.3, with the mean age of patients enrolled being $43 \pm 18.4$ years. A majority, $18(20.5 \%)$ of them were in the 31-40-year age group. Most of the patients i.e. 72 (81.8\%) presented within the first 7 days of illness. The main symptom was fever, seen in 67 (76.3\%) patients. The knee joint was seen to be involved in a majority of patients $60(68.2 \%)$, followed by the elbow joint in 40 (45.5\%) of them. Diabetes mellitus was the most commonly observed co-morbidity, seen in $15(17 \%)$ patients. Co-infection with Dengue was seen in $8(9.1 \%)$ patients, 1 of whom died. 8 (9.1\%) patients demonstrated leucopenia, while $52(59.1 \%)$ had transaminitis. While 67 (76\%) patients required treatment on IPD basis. The mean duration of hospital stay was $4 \pm 3.96$ days. 29 (33\%) patients required the administration of steroids in addition in NSAIDs. Also, 37 (42\%) had arthritis on follow up. Overall, 86 (97.7 \%) patients were discharged while 2 (2.3\%) expired. Both of these patients had documented multisystemic involvement.

\section{CONCLUSIONS}

Chikungunya fever, though a self-limiting disease can be very debilitating, and in its severe form, can cause multiorgan involvement and mortality.

HOW TO CITE THIS ARTICLE: Solomon L, Kumar N, Singh N. Clinical profile of patients with chikungunya fever. J. Evolution Med. Dent. Sci. 2019;8(14):1094-1097, DOI: 10.14260/jemds/2019/242

\section{BACKGROUND}

Chikungunya fever is an arboviral infection, caused by an RNA virus of the Togaviridae family. The virus was first isolated in 1952-53 in Tanzania, and the name Chikungunya itself is derived from a root verb in the African language, which means "that which bends up", referring to the stooped appearance of those affected by the disease due to disabling joint involvement.(1) However the existence of this disease in India has been recorded as early as 1824 . For a century, the outbreaks were focal in nature, however in the past decade or so large outbreaks have occurred in India, the largest of which occurred in 2006 and 2016.

The epidemiological studies done during these outbreaks showed a large burden in terms of DALY's. The typical features of fever and arthralgias may also be accompanied in some patients by complications and atypical features, notably

'Financial or Other Competing Interest': None.

Submission 20-02-2019, Peer Review 24-03-2019,

Acceptance 01-04-2019, Published 08-04-2019.

Corresponding Author:

Dr. Lydia Solomon,

Assistant Professor

Department of Medicine,

Christian Medical College and Hospital,

Dr. Brown Road, Ludhiana-141008, Punjab, India.

E-mail: lydiasolomon777@gmail.com

DOI: $10.14260 /$ jemds/2019/242 myocarditis, acute kidney injury, respiratory failure and cardiovascular decompensation. Laboratory diagnosis is made by the detection of specific CHIKV IgM antibodies in the sera of patients, usually after 5 days of disease onset.

By and large the disease is self-limiting, however in a small percentage of patients, chronic disabling arthritis can ensue, and is found to more frequently occur in those with underlying co-morbidities. This can severely affect a patient's quality of life, leading to chronic fatigue and sadness of mood. No antiviral drug has proved effective against this disease, hence symptomatic treatment comprising rest and the use of NSAIDS to relieve joint pains is the mainstay of treatment.

We experienced an epidemic in the year 2016, wherein patients presented with varying degrees of joint involvement and debility, many of whom required IPD treatment. Hence a decision was made to carry out this observational study to determine the clinical profile, severity of disease and outcome in patients treated on an OPD and IPD basis from the months of September to November 2016.

\section{METHODS}

This was a observational study conducted amongst the IPD and OPD patients who presented to the Department of Medicine, Christian Medical College and Hospital, Ludhiana from September to November 2016. Patients who presented with symptoms suggestive of Chikungunya Fever were tested for CHIKV IgM antibodies, and those who tested positive (88) 
were then included in the study. Clinical information such as age, gender, symptoms including joint involvement, existing co-morbidities, treatment given, and final outcome were documented.

\section{Statistical Analysis}

In the descriptive analysis, continuous variables were expressed as Mean \pm S.D. and categorical variables were expressed as count (percentage).

\section{RESULTS}

A total of 88 patients formed our study group.

The mean age of patients enrolled into the study was $43 \pm 18.4$ years. A majority, 18 (20.5\%) of them were in the 31-40-year age group.

The Male: Female ratio was 1:1.3.

Amongst the 88 patients, 21 (23.8\%) had pre-existing comorbidities, out of which the most common was Diabetes Mellitus, seen in 15 (71.4\%) patients. (Table 1)

\begin{tabular}{|c|c|c|}
\hline Comorbidities & Frequency & Percentage \\
\hline Diabetes Mellitus & 15 & 17.0 \\
\hline $\begin{array}{c}\text { Coronary Artery } \\
\text { Disease }\end{array}$ & 5 & 5.7 \\
\hline Hypertension & 8 & 9.1 \\
\hline \multicolumn{2}{|c|}{ Table 1. Distribution of Patients According to } \\
Comorbidities \\
\hline
\end{tabular}

Co-infection of Dengue with Chikungunya was seen in $8(9.1 \%)$ patients.

Most of the patients i.e. $72(81.8 \%)$ presented within the first 7 days of illness.

$67(76 \%)$ patients required treatment on IPD basis, while the rest could be managed on OPD basis. Among those admitted, the mean duration of hospital stay was $4 \pm 3.96$ days.

Joint pains, fever and rashes were the most common symptoms amongst the patients at presentation, however along with joint pains, which was experienced by all patients, $67(76.1 \%)$ had fever. (Table 2)

\begin{tabular}{|c|c|c|}
\hline Symptoms & Frequency & Percentage \\
\hline Fever & 67 & 76.1 \\
\hline Rashes & 26 & 29.5 \\
\hline Swelling & 14 & 15.9 \\
\hline Table 2. Distribution of Patients According to Symptoms \\
\hline
\end{tabular}

The joint pains were symmetrical, and debilitating, affecting the peripheral joints most commonly i.e. the knees in $60(68 \%)$, elbows in $40(45.5 \%)$ and wrists in $35(39.8 \%)$ patients. (Table 3)

\begin{tabular}{|c|c|c|}
\hline $\begin{array}{c}\text { Involvement of } \\
\text { Joints }\end{array}$ & Frequency & Percentage \\
\hline Wrist & 35 & 39.8 \\
\hline Elbow & 40 & 45.5 \\
\hline Shoulder & 22 & 25.0 \\
\hline Hip & 35 & 39.8 \\
\hline Knee & 60 & 68.2 \\
\hline Ankle & 34 & 38.6 \\
\hline \multicolumn{2}{|c|}{ Table 3. Distribution of Patients According to Involvement } \\
of Joints \\
\hline
\end{tabular}

During the study of laboratory features, it was found that $8(9.1 \%)$ patients had documented leucopenia, while 52 (59.1\%) had transaminitis, out of which 8 (9.1\%) had a value of $>100$ IU/L. (Table 4)

\begin{tabular}{|c|c|c|}
\hline ALT & Frequency & Percentage \\
\hline$<40$ & 36 & 40.9 \\
\hline $40-100$ & 44 & 50.0 \\
\hline$>100$ & 8 & 9.1 \\
\hline \multicolumn{2}{|c|}{ Table 4. Distribution of Patients According to ALT } \\
\hline
\end{tabular}

All patients were administered NSAIDS for symptom relief, however $29(33 \%)$ patients required the additional administration of steroids in view of severe symptoms.

$27(30.7 \%)$ patients were lost to follow up, out of the 58 patients who followed up, 37(63.7\%) had persistent arthritis.

Out of the 88 patients enrolled, 2(2.7\%) expired.

Both belonged to the 31-40-year age group. Both the patients had documented CNS (seizures/quadriparesis) CVS (arrhythmias) renal and haematological complications as described in Table 5.

\begin{tabular}{|c|c|c|c|c|}
\hline $\begin{array}{l}\dot{0} \\
\dot{z}\end{array}$ & $z_{3}^{\infty}$ & $\sum^{2}$ & | & 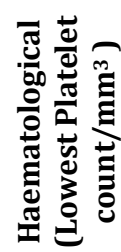 \\
\hline $\begin{array}{c}\text { Patient } \\
1\end{array}$ & Quadriparesis & $\begin{array}{c}\text { Ventricular } \\
\text { Tachycardia }\end{array}$ & 2.1 & 60,000 \\
\hline $\begin{array}{l}\text { Patient } \\
2\end{array}$ & Seizures & $\begin{array}{c}\text { Atrial Fibrillation/ } \\
\text { Ventricular } \\
\text { Tachycardia }\end{array}$ & 1.6 & 9000 \\
\hline \multicolumn{5}{|c|}{ Table 5} \\
\hline
\end{tabular}

\section{DISCUSSION}

The origins of Chikungunya have likely been traced back to Central East Africa, where it has commonly been observed amongst non-human primates and mosquitoes, however in Asia it has been seen to primarily circulate between humans and mosquitoes.(2) Complications such as CNS and cardiac manifestations have also been described, but are rare and has been more commonly observed in extremes of age group and those with underlying co-morbidities. The most notable longterm effect of this disease has been debilitating arthritis, leading to considerable disability.

In our study, all patients presenting with features suggestive of CHIKV were tested, and those found to be positive were enrolled in the study.

The number of females were more than males (M: F ratio 1:1.3). Majority i.e. $18(20.5 \%)$ of the patients were in the age group of 31-40 years.

It is by and large observed to be a self-limiting illness which comprises mainly of fever, rash, arthralgias. In our study also arthralgia (100\%), fever $(76.1 \%)$ and rashes (29.5\%) were the most common presenting symptoms. This corresponds to other studies who noted the occurrence of arthralgia in $85-100 \%$ of people with symptomatic infection. $(3,4,5,6)$

In our study it was observed that the peripheral joints were most commonly involved, the knees in 60 (68\%), elbows in $40(45.5 \%)$ and wrists in 35 (39.8\%) patients. 
Studies by Ali Ou et al, Chow et al, Mathew AJ et al and Chopra A et al also had findings similar to our study, wherein the knee joint was found to be the most commonly involved. $(7,8,9,10)$ However, unlike the findings in our study, Foissac et al, Chopra A et al, Bouquiallard et al, Malvi et al noted that the wrists, metacarpal and interphalangeal joints were more commonly involved.(11,12,13,14)

When laboratory parameters were assessed, leucopenia was observed amongst $8(9.1 \%)$ patients. In contrast some studies observed leucopenia to be a common presentation. $(3,7,15)$

Blood chemistry parameters are usually noted to be normal throughout the disease course, however, similar to studies conducted by Ali et al and Higgs et al, we documented transaminitis in $52(59.1 \%)$ patients, 8 (9.1\%) of whom had a value of $>100 \mathrm{IU} / \mathrm{L}$.

All patients were administered NSAIDS for symptom relief, however 29 (33\%) patients required the additional administration of steroids in view of severe symptoms. Even though steroids are not recommended as the first line of management, in a study conducted by Andrade et al, analgesic non-responsiveness was reported, and the use of steroids was required for symptom relief in $40 \%$ of the study population.(16)

$27(30.7 \%)$ patients were lost to follow up, out of the 58 patients who followed up, 37(63.7\%) had persistent arthritis. This is similar to studies conducted by Brighton et al and Borgherni et al in which $64 \%$ patients were reported to have persistent joint pain/stiffness. ${ }^{17,18)}$

In our hospital, an epidemic of Chikungunya and Dengue occurred during the same months of the year 2016(September-November). In our study, documented coinfection with Dengue was observed in 8 (9.1\%) patients. Similar results were observed in a study conducted by Singh J et al, in which $10.7 \%$ cases were positive for co-infection.(19)

Out of the 88 patients enrolled, 2(2.7\%) expired. Both of them had common manifestations in the form of multiorgan involvement, with documented CNS, CVS, renal and haematological involvement. Also, both belonged to the 3140-year age group. In a study conducted by Gogia et al in Delhi, during the CHIKV outbreak in 2016, out of the 410 patients who tested positive for CHIKV, the mortality rate was found to be $39(9.5 \%)$. Of these, a majority belonged to the elderly age group, as opposed to our study. The kidney was found to be the most common organ involved amongst those who died (95\%), followed by the CNS in $48.7 \%$.(20) $^{(20}$

\section{CONCLUSIONS}

Chikungunya virus infection is associated with a number of challenges, including overlapping symptomatology with other viral infections, and persistent arthralgias, placing a major burden on health care. Also, even though it has a low mortality rate, its symptoms should not be ignored, since in rare cases it can lead to severe multiorgan involvement and mortality.

\section{ACKNOWLEDGEMENTS}

I thank all the patients who gave their consent to be part of this study. I also acknowledge the timely help given by the Microbiology Department, CMC, in testing patients for this study. Mrs. Himani Khatter provided the biostatistical support needed to complete this study, for which I am very grateful.

\section{REFERENCES}

[1] Krutikov M, Manson J. Chikungunya virus infection: an update on joint manifestations and management. Rambam Maimonides Med J 2016;7(4).

[2] Jupp PG, McIntosh BM, Monath TP. Chikungunya virus disease, the arboviruses: epidemiology and ecology. Vol. 2. Boca Raton, FL: CRC Press 1988: p. 137-57.

[3] Powers AM, Brault AC, Tesh RB, et al. Re-emergence of Chikungunya and O'nyong-nyong viruses: evidence for distinct geographical lineages and distant evolutionary relationships. J Gen Virol 2000;81(Pt 2):471-9.

[4] Higgs S, Ziegler SA. A nonhuman primate model of Chikungunya disease. J Clin Invest 2010;120(3):65760.

[5] Sissoko D, Malvy D, Ezzedine K, et al. Post-epidemic Chikungunya disease on Reunion Island: course of rheumatic manifestations and associated factors over a 15-month period. PLoS Negl Trop Dis 2009;3(3):e389.

[6] Waymouth HE, Zoutman DE, Towheed TE. Chikungunya-related arthritis: case report and review of the literature. Semin Arthritis Rheum 2013;43(2):273-8.

[7] Ali Ou Alla S, Combe B. Arthritis after infection with Chikungunya virus. Best Pract Res Clin Rheumatol 2011;25(3):337-46.

[8] Chow A, Her Z, Ong EK, et al. Persistent arthralgia induced by Chikungunya virus infection is associated with interleukin-6 and granulocyte macrophage colony-stimulating factor. J Infect Dis 2011;203(2):149-57.

[9] Mathew AJ, Goyal V, George E, et al. Rheumaticmusculoskeletal pain and disorders in a naïve group of individuals 15 months following a Chikungunya viral epidemic in south India: a population based observational study. Int J Clin Pract 2011;65(12):1306-12.

[10] Chopra A, Anuradha V, Ghorpade R, et al. Acute Chikungunya and persistent musculoskeletal pain following the 2006 Indian epidemic: a 2-year prospective rural community study. Epidemiol Infect 2012;140(5):842-50.

[11] Foissac M, Javelle E, Ray S, et al. Post-Chikungunya rheumatoid arthritis, Saint Martin. Emerg Infect Dis 2015;21(3):530-2.

[12] Chopra A, Anuradha V, Lagoo-Joshi V, et al. Chikungunya virus aches and pains: an emerging challenge. Arthritis Rheum 2008;58(9):2921-2.

[13] Bouquillard E, Combe B. A report of 21 cases of rheumatoid arthritis following Chikungunya fever. A mean follow-up of two years. Joint Bone Spine 2009;76(6):654-7.

[14] Malvy D, Ezzedine K, Mamani-Matsuda M, et al. Destructive arthritis in a patient with chikungunya virus infection with persistent specific IgM antibodies. BMC Infect Dis 2009;9:200.

[15] Sebastian MR, Lodha R, Kabra SK. Chikungunya infection in children. Indian J Pediatr 2009;76(2):1859. 
[16] De Andrade DC, Jean S, Clavelou P, et al. Chronic pain associated with the Chikungunya fever: long lasting burden of an acute illness. BMC Infect Dis 2010;10:31.

[17] Brighton SW, Prozesky OW, de la Harpe AL. Chikungunya virus infection. A retrospective study of 107 cases. S Afr Med J 1983;63(9):313-5.

[18] Borgherini G, Poubeau P, Jossaume A, et al. Persistent arthralgia associated with Chikungunya virus: a study of 88 adult patients on Reunion Island. Clin Infect Dis 2008;47(4):469-75.
[19] Singh J, Dinkar A, Singh RG, et al. Clinical profile of dengue fever and co-infection with Chikungunya. Ci Ji Yi Xue Za Zhi 2018;30(3):158-64.

[20] Gogia A, Sairam B, Kakar A. Chikungunya: a mortality report. Open Forum Infectious Diseases 2017;4(Suppl 1): S518. 